\title{
Reviews
}

\section{Suicidal Behaviour among People with HIV and AIDS. \\ Global Programme on AIDS - World Health Organisation. 1990.}

This extremely slim booklet ( 13 pages) is the report of a group of researchers in the AIDS field on current knowledge about the association between suicidal behaviour, both fatal and non-fatal, and AIDS and HIV infection. It also contains the group's recommendations about future research needs. The brevity of the document is a reflection of the paucity of information in this area.

It has been claimed that the risk of suicidal behaviour may be increased at various stages in relation to HIV infection and AIDS. The first phase might be when HIV infection is feared, but without testing having been conducted. This would include individuals with 'AIDS phobia'. The second is when a person has been tested and found to be HIV positive. Both possible risk points emphasise the need for proper pre- and post-test counselling. The third risk phase might be when AIDS symptoms first appear. The fourth phase is in the terminal stages of AIDS. One might question whether the prevention of suicide in this fourth stage is a legitimate aim. However, suicidal ideation in AIDS victims may well be due to depression, perhaps secondary to social stigmatisation and loss of family support or to neuropsychiatric complications of the disease. This document reasonably argues that prevention, especially through appropriate treatment for depression, might allow people the chance to evaluate their situation more rationally and sort out their affairs.

While suicidal ideation at some time is probably extremely common (if not universal) in people who are HIV positive and in AIDS sufferers, actual suicidal behaviour is probably more likely in those with certain background characteristics, especially a history of earlier suicidal behaviour. Such factors should be considered when assessing suicidal potential.

So what facts are known about risk of suicidal behaviour in this population? The answer is very little. Studies in the USA have suggested that suicide is 16-36 times more common in people with AIDS than in the general population. However, failure or inability to control for other risk factors for suicide (e.g. drug abuse) may have resulted in an overestimate of the degree of risk specifically attributable to AIDS. On the other hand, many HIV-related suicides are probably not identified, partly because some suicidal deaths are simply not being recorded as such, and partly because some deaths will be ascribed to complications of the disease without AIDS being mentioned in the Coroners' records. One cannot help wondering if the recent increase in suicides in young males in the UK could in any way be related to HIV infection or AIDS.

The document ends by making strong pleas for more reliable information. Some should come from long-term prospective follow-up studies currently under way. A particularly sensible request is that forensic institutes and pathology departments should do confidential post-mortem testing for HIV seropositivity in anyone dying suddenly of external violence or poisoning or otherwise under unclear or suspicious circumstances. HIV status could then be linked to background information about the deceased persons in order to provide a much fuller picture of the risk factors for suicide in people who are HIV positive or have AIDS.

Psychiatrists are likely to become more familiar with the problem of suicidal behaviour in this population as the number of AIDS cases increases. At present we clearly have very little information on which to base preventive and treatment strategies, or even to plan broad policies.

Consultant Psychiatrist and Clinical Lecturer

Warneford Hospital and University

Department of Psychiatry

Oxford OX3 $7 J X$

Working Out: setting up and running community psychogeriatric teams.

Edited by James Lindesay. 1991. Pp. 64. Copies are available from RDP, 134-138 Borough High Street, London SE1 1LB. £3 inclusive.

This short book summarises the proceedings of two seminars hosted by Research and Development for Psychiatry on the organisation of community teams in old age psychiatry. Two such teams are described although one could only estimate their success by reading between the lines. Other authors discussed factors influencing success, the question of evaluation and the general context within such teams must operate.

Describing one of a number of teams set up in York, Christine Kirk demonstrated the importance of careful ground work, effective and committed leadership and respect for the personal and specialised skills of members of the team. She warned of the 
danger of over-selling the team's capacity at the outset and stressed the need for the team to foster its links with other parts of the service. I felt that I needed to know whether the team was actually doing a good job but it seemed from the account from its evaluator, Anne Pattie, that it was and that it had been seen as one of the best of its type in York. Alastair MacDonald's analysis of his team in Lewisham sadly included no indication of its effectiveness. Here there was more blurring of roles with the contribution of the consultant apparently substantially less. This, with the flippancy of the commentary and the apparent poverty of the links with GPs and geriatricians, smacked of an alibi for consultant detachment rather than a positive recipe for an effective service.

Øvretveit presented some general principles about team organisation, stressing the positive values of preliminary groundwork, clear objectives, good communication, recognition of the value and different roles of team members and accommodation within the team for the input of professional line managers. In his and Lindsay's summarising chapter there seemed general agreement as to the value of a common base and the establishment of leadership and, through that, accountability to the management of the parent service. Leiper's discussion of evaluation got rather bogged down in quality assurance. Elaine Murphy's very sensible little contribution stressed the importance of the team's roles within the service as a whole and the need to direct and present its work in a way that was relevant to the new era of purchaser-provider contracts and partnership in community care.

If found bits of this book interesting and bits irritating. It was useful in making one reflect on how one's own service worked. I found the concept of the community team as a separate entity difficult to accept unless along the lines of the offensive or defensive teams or the running backs of an American football squad. No prizes for guessing whom I would see as quarter-back, though I would prefer to invest a post of player-coach.

\section{Consultant in Old Age Psychiatry \\ Moorgreen Hospital, Southampton}

COLIN GODBer

\section{Community Psychiatric Nursing: The 1990 National}

Survey.

By Edward White. Pp. 22. Community Psychiatric

Nurses Association, 74 Lutterworth Road,

Nuneaton, Warwickshire CV11 6PH. $£ 7.50$ plus 60p postage and packing; Directory $£ 7.50$ plus 60 p

$p$ and $p ; £ 12.50$ for both plus $£ 1.20 p$ and $p$.

This is a survey of CPN services in Britain in 1990. It is the third quinquennial survey of CPN services and allows one to get a feel of the developments that have taken place since 1980 . Obviously, because of administrative changes, not all the measures used are totally comparable but most are. The breakdown is both by region and types of service so you can place your own situation in both the national and local context.

It's full of useful information and I am sure will be invaluable to hospital and nurse managers. It suffers in style by trying to be too scientific and guarding against any possible criticisms of methodological inadequacy (CPNs have clearly felt battered by their non-nursing colleagues). While this is important in strengthening the growing academic credentials of CPNs, it makes for unnecessarily heavy reading. At $£ 7.50$ for 20 pages it is not likely to be a best-seller but certainly a publication worth obtaining for most services.

Consultant Psychiatrist

TOM BURNS

St George's Hospital, Tooting SW17 